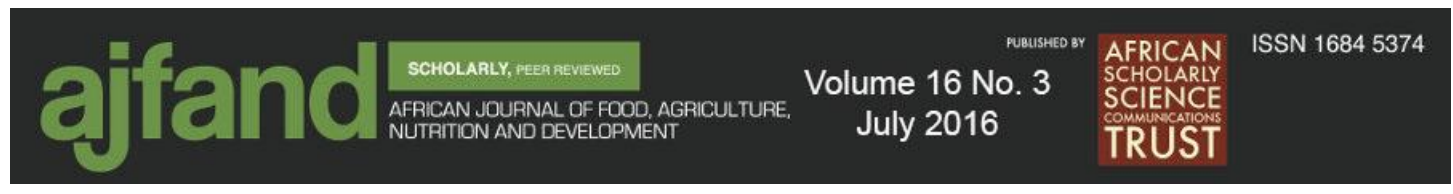

\title{
10.18697/ajfand.75.ILRI11
}

\section{A REVIEW OF AGRICULTURAL AFLATOXIN MANAGEMENT STRATEGIES AND EMERGING INNOVATIONS IN SUB-SAHARAN AFRICA}

\author{
Monda $\mathrm{EO}^{1^{*}}$ and AE Alakonya ${ }^{2}$
}

*Corresponding author email: ethelmonda@gmail.com

${ }^{1}$ Kenyatta University, Department of Microbiology, P.O. Box 43844, 00100 Nairobi, Kenya

2 Jomo Kenyatta University of Agriculture and Technology, Institute for Biotechnology Research, P.O. Box 62000, 00200 Nairobi, Kenya 


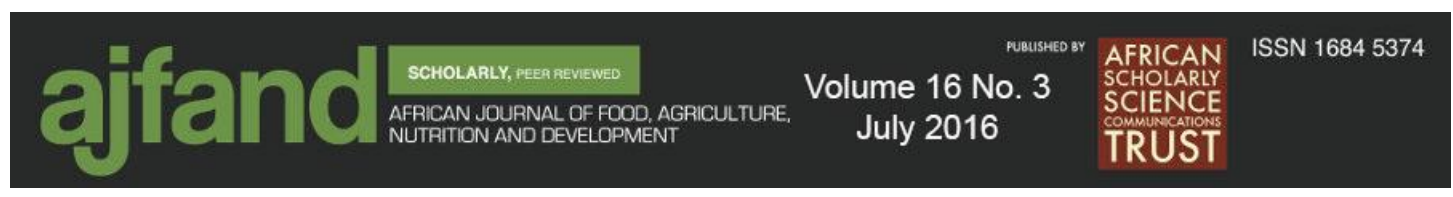

\begin{abstract}
Aflatoxins are highly carcinogenic secondary metabolites produced by Aspergillus flavus, A. parasiticus and A. nomius. Aflatoxin contamination of food and animal feeds is, therefore, a major food security, food safety, trade, human and domestic animal health concern. Researchers worldwide have suggested various agriculture-based strategies to manage aflatoxigenic Aspergillus species and reduce contamination to safe levels. This paper reviews various agricultural strategies that could be employed to reduce contamination of aflatoxins in food crops and animal feeds, as well as the challenges faced by these reduction strategies. Among these strategies are innovations like Aflasafe $^{\mathrm{TM}}$ and solar grain driers. It is hoped that this critique will stimulate refinement of the existing aflatoxin control approaches and innovations to maximize their efficacy.
\end{abstract}

Key words: aflatoxins, plant resistance, atoxigenic strains, drying instruments, aflatoxin control, food safety, mycotoxins, post-harvest losses 


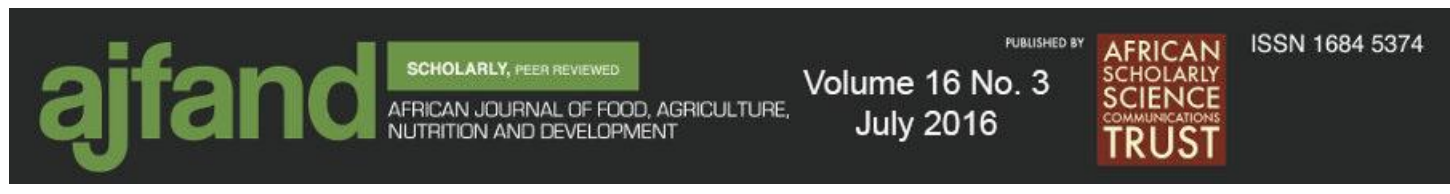

\section{INTRODUCTION}

Aflatoxins are secondary metabolites produced by the fungi Aspergillus flavus, A. parasiticus and A.nomius. The first two species contaminate a variety of staple foods including maize, groundnuts and tree nuts with aflatoxins. Contamination of food crops with aflatoxins results in negative health impacts to both humans and animals. Further, such food is prevented from accessing certain markets, resulting in economic losses [1]. Aflatoxins may occur in crops in the field during growth or drying and also in storage if kept in sub-optimal conditions. Aspergillus parasiticus is mostly associated with contamination of groundnuts while A. flavus is the common contaminant of maize [2,3]. Aspergillus flavus produces aflatoxin $\mathrm{B}_{1}$ and $\mathrm{B}_{2}$ while $A$. parasiticus produces aflatoxin $\mathrm{B}_{1}, \mathrm{~B}_{2}, \mathrm{G}_{1}$ and $\mathrm{G}_{2}$. Aspergillus nomius is rarely associated with agricultural contamination [4]. Aspergillus flavus and A. parasiticus infect their hosts while in the field while either growing or drying and continue to proliferate in the harvested grains if stored with above 13\% moisture content. According to the Food and Agriculture Organization of the United Nations (FAO), 25\% of world's food crops are contaminated with mycotoxins [5]. In sub-Saharan Africa, where most people are resource-poor, there is high exposure to aflatoxins through dietary staples like maize and groundnuts. Given the economic and health impacts associated with aflatoxin exposure in sub-Saharan Africa, it is imperative that the toxin is more effectively managed, especially in staple food crops.

\section{Impact of aflatoxins on human and animal health}

According to the International Agency for Research on Cancer (IARC), aflatoxins are classified as Group I carcinogens, causing liver cancer (hepatocellular carcinoma) in humans [6]. Global risk assessment studies associate between 25,200 and 155,000 human liver cancer cases per year with aflatoxin exposure[7]. Aflatoxins have also been reported to cause immune suppression in children and there is an association between aflatoxins and stunting in children [8-10] as well as lower weight babies at birth [11, 12], but this has not been proven to be a causal relation. In Kenya, consumption of aflatoxincontaminated maize affected 317 people with 125 deaths in 2004 [13]. This is thought to be the worst case of aflatoxicosis reported. Analysis of the maize samples revealed that the aflatoxicosis was caused by the S-strain of A. flavus [13, 14]. A summary of other adverse effects of aflatoxin exposure to human health is given in $\mathrm{Wu}$ et al.[15]. Two other aflatoxin producing species have been reviewed by Varga et al.[16]. Apart from aflatoxins, A. flavus produces cyclopiazonic acid, a toxin with the ability to induce various pathological lesions in test animals [17].

\section{Pre-harvest agricultural management of aflatoxins}

\section{a. Biological control, its mechanism and challenges}

Aspergillus flavus is predominantly a saprophytic fungus in soil but is also opportunistic and colonizes in environments rich in carbon and nitrogen. Two strains of A. flavus, $\mathrm{S}$ and L, have been reported [2]. Both $\mathrm{S}$ and L strains have globally been reported in maize fields. The $\mathrm{S}$ strain produces more aflatoxins and sclerotia (dormant body of fungus) but fewer conidia (asexual spores).The $\mathrm{S}$ and $\mathrm{L}$ strains also differ in the size of a deletion in the norB-cypA region of aflatoxin gene cluster [18]. A high concentration of $\mathrm{S}$ strain is correlated with outbreaks of aflatoxin contamination. An 
important biocontrol strategy is to introduce an atoxigenic strain to the crop environment to compete with toxigenic strain $[19,20]$. Atoxigenic strains are nonaflatoxin producing strains of $A$. flavus that out-compete the toxigenic strain(s) in the soil. Atoxigenic strains that have been applied in fields include NRRL 21882, which is an active ingredient in Afla-Guard [21] and Aflasafe ${ }^{\mathrm{TM}}$ that is being tested in fields in a number of African countries including Nigeria, Kenya, Zambia and Senegal. In each country, Aflasafe ${ }^{\mathrm{TM}}$ consists of a combination of local atoxigenic strains.

Co-inoculation of maize with toxigenic and atoxigenic strain (AF13) results in reduced aflatoxin contamination by $80-95 \%$ due to competitive exclusion/displacement of toxigenic strain by atoxigenic strain [22]. Others report aflatoxin reduction by up to $66 \%$ when atoxigenic strain NRRL 21882 (Afla-Guard) - Syngenta was applied to the soil [23]. It appears that touching or close physical interaction is necessary for atoxigenic strains to outcompete toxigenic strains [24, $25]$. It could be appropriate to apply multiple control strains with different spectra of touch inhibition ability in order to increase the effectiveness of biocontrol [25]. It has also been hypothesized that competitive exclusion due to competition for nutrients is involved in out-competition.

A potential drawback of biocontrol is the possibility of cytoplasm fusion and nuclear fusion between toxigenic and atoxigenic A. flavus strains leading to production of ascospores (sexually-produced spores). The atoxigenic biocontrol strain could acquire aflatoxin pathway genes through vegetative fusion (parasexual or sexual reproduction) and this could exacerbate the aflatoxin contamination problem. There has been demonstration in vivo of sexual reproduction in A. flavus where undeveloped stromata (sexual structure) were found in naturally infected maize ears and developed to ascocarps with viable ascospores [26]. It has also been reported that $A$. flavus can undergo sexual reproduction with A.minisclerotigenes [27]. Stress to the fungi could lead to increased level of sexual reproduction [28]-especially when A. flavus experiences high temperatures and drought [29]. Recombination has also been detected between aflatoxigenic and non-aflatoxigenic A. flavus with some offspring regaining the ability to produce aflatoxins [29]. Another challenge is that farmers need to apply the biocontrol strain annually, which can be expensive for resourcepoor farmers. Also, plant stress due to climate change or other factors may weaken the defense mechanism, thereby facilitating A. flavus infection even in the presence of biological control (increased water stress is correlated with increased aflatoxin production) [30, 31]. Challenges to the biocontrol strategy for prevention of aflatoxin contamination can therefore be summarized as:(a) diversity of $A$. flavus populations, (b) ability of sexual reproduction, (c) plant stress overcoming biological control, (d) lack of consistent aflatoxin reduction by biocontrol and(e) the cost of biocontrol [32, 33].

\section{b. Enhanced plant resistance against aflatoxins}

Efforts to enhance plant resistance to aflatoxin contamination in maize have mainly focused on resistance to the fungus, inhibition of aflatoxin production and resistance to insects [34]. 


\section{i. Resistance breeding against Aspergillus flavus and aflatoxin}

Genetic variation for resistance to aflatoxin contamination is possibly available in maize and, therefore, identification and development of plant resistance to aflatoxins could be a durable, desirable and feasible control option [35]. Screening for plant resistance to aflatoxins is mainly done in the field; hence it is influenced by host-induced environmental reactions. It has been noted that aflatoxin resistance genes are polygenic, hence the need for gene pyramiding (method aimed at assembling multiple desirable genes from multiple parents into a single genotype for specific trait) using numerous genotypes with novel genes [35]. The need for effective, reliable and rapid screening techniques for breeding for resistance to aflatoxins accumulation in maize has led to development of improved inoculation methods as well as in vitro screening protocols such as the Kennel Screening Assay, which have resulted in identification of more promising sources of resistance to aflatoxins [36-38].

The genetics behind aflatoxin resistance are quantitatively inherited and complex with additive gene effects playing a major role in conditioning the inheritance of resistance [39, 40]. While germplasm exhibiting aflatoxin resistance has been identified, other approaches like gene pyramiding could be applied for further breeding to increase long-term aflatoxin resistance. Finally, efforts to reduce aflatoxin contamination through breeding should be enhanced by greater knowledge of gene function and expression under a range of environmental conditions in preparation to face increased aflatoxin levels predicted in the future owing to climate change and global warming [41]. The use of gene expression assays like microarray analysis has led to the identification of several maize genes that are induced during infection with A. flavus in susceptible and resistant maize lines [42].Proteomic studies have shown higher protein activity in resistant than in susceptible germplasm especially the antifungal proteins $\beta-1,3-$ glucanase, constitutive kernel proteins and catalase proteins [43-46]. The major challenge with breeding for resistance is that the traits associated with aflatoxin resistance are polygenic and, therefore, could take many breeding seasons to come up with a resistant variety. Further, some of the resistant varieties are not adapted or do not yield well in the agro-ecologies endemic to aflatoxin contamination. There are additional challenges in delivery of improved genotypes to poor farmers.

\section{ii. Transgenic approaches towards Aspergillus flavus and aflatoxin-resistant maize}

A transgenic approach has several advantages over other potential aflatoxin control methods such as conventional breeding and biological control. For instance, such approaches shorten the time taken to come up with a product and are easily adaptable to the smallholder setting since all farmers need to do is to acquire transgenic seeds. Additional costs are, therefore, not levied to the farmer other than the purchase of seed if a transgenic approach is adopted. These approaches in management of aflatoxins have mainly focused on expression of recombinant insecticidal proteins from Bacillus thuringiensis (Bt), expression of antifungal peptides and proteins and the use of Host Induced Gene Silencing technology. The focus on resistance to insects is because of a correlation between 
insect damage and aflatoxin contamination. The use of $B t$ toxin technology against the European corn borer has enabled a reduction of aflatoxin levels in maize [47].

Some proteins are also known to inhibit fungal growth or aflatoxin production. Expressing these proteins that can reduce fungal infection as well as enzymes that can degrade toxins (detoxifying enzymes) or proteins that block the toxin biosynthetic pathway could lead to low A. flavus colonization as well as aflatoxin accumulation in maize [48].Many antifungal genes have been identified through comparative proteomics between aflatoxin resistant and susceptible maize lines. Furthermore, the process that $A$. flavus uses to convert kernel starch into simple sugars has been key to both the infection of maize host tissue and the production of aflatoxin. For instance, an amy-1 $\alpha$-amylase gene in A. flavus has been identified as a key enzyme in the synthesis of aflatoxins [49]. Currently, two maize inhibitors of $A$. flavus $\alpha$-amylase have been identified and their expression in transgenic maize resulted in reduced colonization and aflatoxin levels. This suggests that expression of $\alpha$-amylase in transgenic maize might reduce both fungal growth and aflatoxin accumulation. The efficacy of antifungal peptides has effectively been demonstrated by several studies and could be a promising management strategy against $A$. flavus [50].

Currently, it is possible to control phytopathogenic fungi through Ribonucleic Acid interference (RNAi) of essential fungal gene(s) expression through the host. This phenomenon is also called 'trans-gene silencing' or 'host induced gene silencing' (HIGS). In fungi, this strategy has been reported in control of Fusarium verticillioides, F. graminearum, Puccinia striiformis f.sp. tritici and A. flavus [51]. Generally, these studies suggest that there exists a micro RNA (miRNA) or small interfering RNAs (siRNAs) trafficking channel between plant hosts and their fungal pathogens. This channel could, therefore, set up a new platform in the management of economically important fungal pathogens including aflatoxigenic A. flavus. With the now available A. flavus genome and the complete elucidation of the aflatoxin biosynthetic pathway, there exist possible targets in A. flavus that could be manipulated to either limit fungal growth or aflatoxin biosynthesis $[52,53]$. Numerous gene function studies on the aflatoxin biosynthetic pathway have identified the transcription factor aflR as a potential in planta target against aflatoxin accumulation [54]. A follow-up study on this prediction by a research group in Kenya led to the transformation of aflR hairpin constructs into a susceptible tropical maize line resulting in a significant (14-fold) reduction in aflatoxin levels. While these results were commendable, the transgenic maize had an altered plant phenotype possibly due to HIGS mistargeting by aflRsi RNAs [55]. Consequently, this study creates a platform from which the effects of silencing other aflatoxin biosynthetic genes on aflatoxin levels could be evaluated.

The major challenges of transgenic approaches are (a) poor farmers find it difficult to adopt new seed technologies, (b) additional regulatory barriers to 


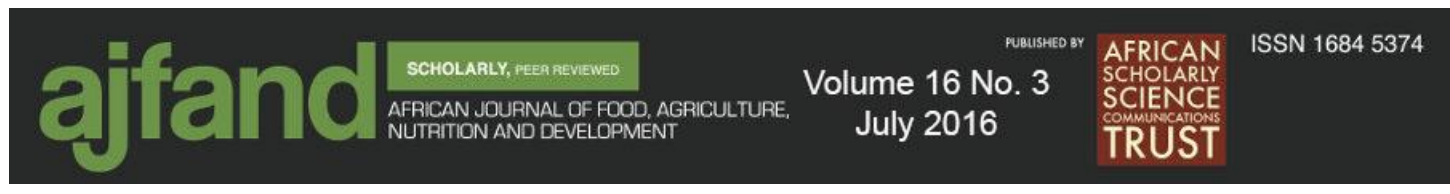

approval of biotechnology crops and (c) some distrust of transgenics among consumers.

\section{Post-harvest agricultural management of aflatoxins}

Post-harvest contamination with aflatoxin is due to infestation with aflatoxigenic Aspergillus species at pre-harvest stage, sub-optimal management practices and adverse conditions at post-harvest. High grain moisture also increases post-harvest aflatoxin contamination. It is, therefore, imperative to dry maize to a kernel moisture level of $13 \%$ and groundnuts to $7 \%$, as aflatoxin levels increase in food during storage. Some of the predisposing factors to aflatoxin contamination in maize and groundnuts are excessive heat, high humidity, lack of aeration in stores and insect and rodent damage [56]. Improved post-harvest handling is, therefore, important for reduction in losses and aflatoxin contamination levels. Post-harvest management stages for maize and groundnuts include cleaning, grading, transportation, storage, processing, packaging and retailing at the market [56]. Good post-harvest strategies include harvesting at the right crop maturity, drying, cleaning of extraneous matter, and good post-harvest storage practices. Sorting to remove small, shrivelled seeds, stained seeds and damaged seeds can also help to minimize aflatoxin levels. Good agricultural practices include early harvesting, proper drying, physical separation, sanitation, proper storage, insect management and resistance breeding but the key factors are proper drying and proper storage.

For post-harvest contamination, three strategies are used to manage aflatoxin contamination: (a) prevention of exposure to the toxin, (b) decontamination and (c) continuous surveillance and monitoring of moulds. Since high grain moisture increases aflatoxin contamination, it would be useful for smallholder farmers to have access to affordable drying devices. This is a focus of AflaSTOP, a project funded by the United States Agency for International Development with Meridian Institute as the lead implementing partner. In this project, ACDI/VOCA (Agricultural Cooperative Development International / Volunteers in Overseas Cooperative Assistance) a private nonprofit organization, is testing suitable, low-cost devices for drying and storage of maize and other products. The low-cost storage devices under evaluation are Purdue Improved Crop Storage bags, Grain Pro Super Grain Bag and traditional polypropylene bags. Drying devices being evaluated include a column dryer, a shallow bed dryer and a solar dryer [57]. The findings from this study could bring us closer to post-harvest aflatoxin reduction in stored grains.

The challenges of post-harvest approaches are (a) some equipment are expensive and either require large capital investments or are unaffordable by the farmers, (b) it is difficult to ensure some of the technologies are widely shared by the affected communities as some are difficult to transport and (c) change in weather could affect the operation of some technologies like solar driers at the time of need.

\section{CONCLUSION}

It is clear from this review that there are a number of agricultural strategies for management of aflatoxins in crops but more research is still required. Strategies need to 


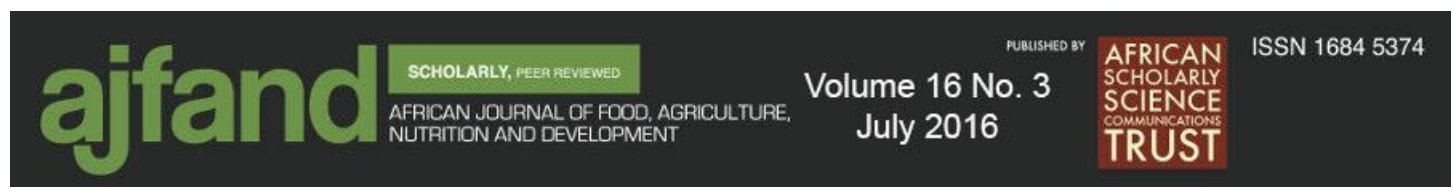

be carefully evaluated to ensure that the aflatoxin problem is not exacerbated and that whatever solution is championed is also affordable and accessible to resource-poor farmers. A combination of strategies could be employed, such as good agricultural practices and affordable storage devices. There is also a need to isolate more atoxigenic strains of A. flavus in order to determine their efficacy in aflatoxin reduction. While further studies to evaluate genes through over expression and gene knockout approach could be promising, the acceptability of transgenic crops in sub-Saharan Africa remains a challenge due to consumer scepticism. 


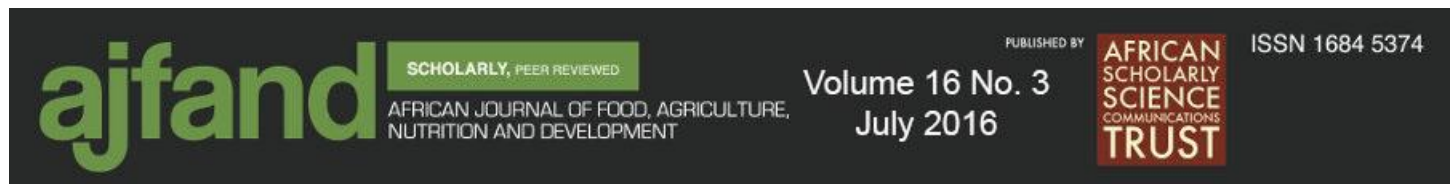

\section{REFERENCES}

1. Robens $\mathbf{J}$ and $\mathbf{K}$ Cardwell The Costs of Mycotoxin Management to the USA: Management of Aflatoxins in the United States. Informa, UK, 2003.

2. Cotty PJ Aflatoxin-producing Potential of Communities of Aspergillus section Flavi from Cotton Producing Areas in the United States. Mycol. Res. 1997; 101(6): 698-704.

3. Kiswii TM, Monda EO, Okemo PO, Bii C and AE Alakonya Efficacy of Selected Medicinal Plants from Eastern Kenya against Aspergillus flavus. J. Plant Sci. 2014; 2(5): 226.

4. Cardwell KF and PJ Cotty Distribution of Aspergillus section Flavi among Field Soils From the Four Agroecological Zones of the Republic of Benin, West Africa. Plant Dis. 2002; 86(4): 434-439.

5. Boutrif E and C Canet Mycotoxin Prevention and Control FAO Programmes. Rev. Med. Vet. (Toulouse) 1998; 149(6): 681-694.

6. International Agency for Research on Cancer IARC Monographs on the Evaluation of Carcinogenic Risks to Humans. Some Naturally Occurring Substances: Food Items and Constituents, Heterocyclic Aromatic Amines and Mycotoxins. 56th ed. IARC Press, Lyon, 1993.

7. Palliyaguru DL and F Wu Global Geographical Overlap of Aflatoxin and Hepatitis C: Controlling Risk Factors for Liver Cancer Worldwide. Food Addit. Contam. Part A. 2013; 30(3): 534-540.

8. Gong YY, Cardwell KF, Hounsa A, Egal S, Turner PC, Hall AJ, and CP Wild Dietary Aflatoxin Exposure and Impaired Growth in Young Children From Benin and Togo: Cross Sectional Study. Br. Med. J. 2002; 325(7354):20-21.

9. Khlangwiset $\mathbf{P}$, Shephard GS and $\mathbf{F}$ Wu Aflatoxins and Growth Impairment: A Review. Crit. Rev. Toxicol. 2011; 41(9): 740-755.

10. Jolly P, Jiang Y, Ellis W, Sheng-Wang J, Afriyie-Gyawu E, Phillips T and J Williams Modulation of the Human Immune System By Aflatoxin. In: Leslie JF, Bandyopadhyay R and A Visconti (Eds). Mycotoxins Detection Methods, Management, Public Health and Agricultural Trade.Oxford, UK: CABI Publishing, 2008. 41-52.

11. Shirima CP, Kimanya ME, Kinabo JL, Routledge MN, Srey C, Wild CP and YY Gong Dietary Exposure to Aflatoxin and Fumonisin Among Tanzanian Children as Determined Using Biomarkers of Exposure. Mol. Nutr. Food Res. 2013; 57(10): 1874-1881. 


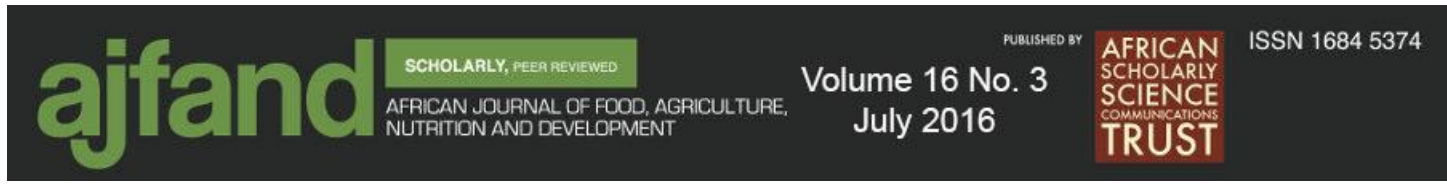

12. Shuaib FMB, Jolly PE, Ehiri JE, Yatich N, Jiang Y, Funkhouser E, Person SD, Wilson C, Ellis WO, Wang J-S and JH Williams Association Between Birth Outcomes and Aflatoxin B1 Biomarker Blood Levels in Pregnant Women in Kumasi, Ghana. Trop. Med. Int. Health 2010; 15(2): 160-167.

13. Probst C, Njapau $\mathbf{H}$ and PJ Cotty Outbreak of an Acute Aflatoxicosis in Kenya in 2004: Identification of the Causal Agent. Appl. Environ. Microbiol. 2007; 73(8): 2762-2764.

14. Probst C, Bandyopadhyay $\mathbf{R}$ and PJ Cotty Diversity of Aflatoxin-Producing Fungi and their Impact on Food Safety in Sub-Saharan Africa. Int. J. Food Microbiol. 2014; 174: 113-122.

15. Wu F, Groopman JD and JJ Pestka Public Health Impacts of Foodborne Mycotoxins. Annu. Rev. Food Sci. Technol. 2014; 5: 351-372.

16. Varga J, Frisvad JC and RA Samson Two New Aflatoxin Producing Species, and an Overview of Aspergillus section Flavi. Stud. Mycol. 2011; 69(1): 57-80.

17. Burdock G and W Flamm Review Article: Safety Assessment of the Mycotoxin Cyclopiazonic Acid. Int. J. Toxicol. 2000; 19(3): 195-218.

18. Ehrlich KC, Chang P-K, Yu J and PJ Cotty Aflatoxin Biosynthesis Cluster Gene cypA is Required for G Aflatoxin Formation. Appl. Environ. Microbiol. 2004; 70(11): 6518-6524.

19. Cotty PJ and P Bayman Competitive Exclusion of a Toxigenic Strain of Aspergillus flavus by an Atoxigenic Strain. Phytopathology 1993; 83(12): 12831287.

20. Horn BW and JW Dorner Effect of Competition and Adverse Culture Conditions on Aflatoxin Production by Aspergillus flavus through Successive Generations. Mycologia 2002; 94(5): 741-751.

21. Dorner JW, Cole RJ and DT Wicklow Aflatoxin Reduction in Corn Through Field Application Of Competitive Fungi. J. Food Prot. 1999; 62(6): 650-656.

22. Brown RL, Cotty PJ and TE Cleveland Reduction in Aflatoxin Content of Maize by Atoxigenic Strains of Aspergillus flavus. J. Food Prot. 1991; 54(8): 623626.

23. Abbas HK, Zablotowicz RM, Horn BW, Phillips NA, Johnson BJ, Jin X and CA Abel Comparison of Major Biocontrol Strains of Non-aflatoxigenic Aspergillus flavus for the Reduction of Aflatoxins and Cyclopiazonic Acid in Maize. Food Addit. Contam. Part A. 2011; 28(2): 198-208. 


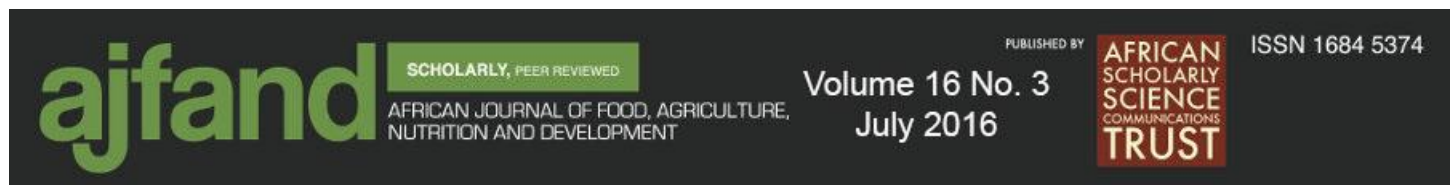

24. Mehl HL and PJ Cotty Variability in Competitive Ability Among Aspergillus flavus Vegetative Compatibility Groups During Maize Infection. Phytopathology 2008; 98(6): S103-S103.

25. Dorner JW Biological Control of Aflatoxin Contamination in Corn Using a Nontoxigenic Strain of Aspergillus flavus. J. Food Prot. 2009; 72(4): 801-804.

26. Horn BW, Olarte RA, Peterson SW and I Carbone Sexual Reproduction in Aspergillus tubingensis from Section Nigri. Mycologia 2013; 105(5): 1153-1163.

27. Geiser DM, Pitt JI and JW Taylor Cryptic Speciation and Recombination in the Aflatoxin-producing Fungus Aspergillus flavus. Proc. Nat. Acad. Sci. USA 1998; 95(1): 388-393.

28. Reverberi M, Punelli M, Scala V, Scarpari M, Uva P, Mentzen WI, Dolezal AL, Woloshuk C, Pinzari F, Fabbri AA, Fanelli C and GA Payne Genotypic and Phenotypic Versatility of Aspergillus flavus during Maize Exploitation. PLOS ONE 2013; 8(7): e68735.

29. Mohale S, Medina A and N Magan Effect of Environmental Factors on in vitro and in situ Interactions Between Atoxigenic and Toxigenic A. flavus Strains and Control of Aflatoxin Contamination of Maize. Biocontrol Sci. Technol. 2013; 23(7): 776-793.

30. OLarte RA, Horn BW, Dorner JW, Monacell JT, Singh R, Stone EA and I Carbone Effect of Sexual Recombination on Population Diversity in Aflatoxin Production by Aspergillus flavus and Evidence for Cryptic Heterokaryosis. Mol. Ecol. 2012; 21(6): 1453-1476.

31. Cotty PJ and R Jaime-Garcia Influences of Climate on Aflatoxin Producing Fungi and Aflatoxin Contamination.Int. J. Food Microbiol. 2007; 119(1-2): 109115 .

32. Wu F Global Impacts of Aflatoxin in Maize: Trade and Human Health. World Mycotoxin J. 2015; 8(2): 137-142.

33. Wu F and P Khlangwiset Health Economic Impacts and Cost-Effectiveness of Aflatoxin-Reduction Strategies in Africa: Case Studies in Biocontrol and PostHarvest Interventions. Food Addit. Contam. Part A. 2010; 27(4): 496-509.

34. Widstrom NW The Aflatoxin Problem with Corn Grain. Adv. Agron. 1996; 219280 .

35. Brown RL, Chen ZY, Menkir A, Cleveland TE, Cardwell K, Kling J and DG White Resistance to Aflatoxin Accumulation in Kernels of Maize Inbreds Selected for Ear Rot Resistance in West and Central Africa. J. Food Prot. 2001; 64(3): 396-400. 


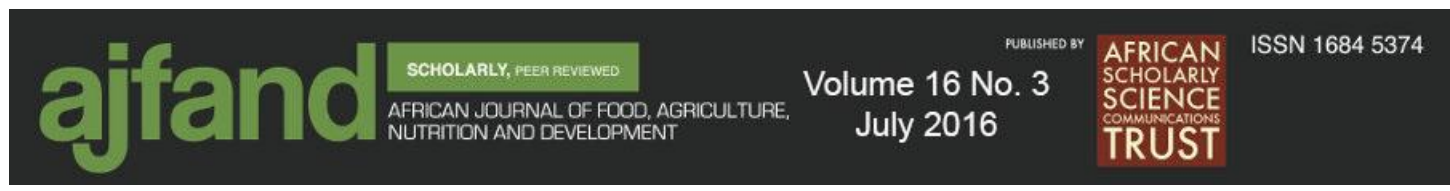

36. Williams WP, Windham GL and PM Buckley Enhancing Maize Germplasm with Resistance to Aflatoxin Contamination. J. Toxicol.-Toxin Rev. 2003; 22(23): 175-193.

37. Henry WB, Windham GL and MH Blanco Evaluation of Maize Germplasm for Resistance to Aflatoxin Accumulation. Agronomy 2012; 2(4): 28-39.

38. Menkir A, Brown RL, Bandyopadhyay R, and TE Cleveland Registration of Six Tropical Maize Germplasm Lines with Resistance to Aflatoxin Contamination. J. Plant Regist. 2008; 2(3): 246.

39. Rajasekaran K, Sickler CM, Brown RL, Cary JW and D Bhatnagar Evaluation of Resistance to Aflatoxin Contamination in Kernels of Maize Genotypes Using a GFP-Expressing Aspergillus flavusStrain. World Mycotoxin J. 2013; 6(2): 151-158.

40. Williams WP and GL Windham Registration of Mp718 and Mp719 Germplasm Lines of Maize. J. Plant Regist. 2012; 6(2): 200.

41. Medina A, Rodriguez A and N Magan Effect of Climate Change on Aspergillus flavus and Aflatoxin B1 production. Front. Microbiol. 2014; 5: 348.

42. Luo M, Brown RL, Chen Z-Y, Menkir A, Yu J and D Bhatnagar Transcriptional Profiles Uncover Aspergillus flavus-induced Resistance in Maize Kernels. Toxins. 2011; 3(7): 766-786.

43. Chen ZY, Brown RL, Cleveland TE, Damann KF and JS Russin Comparison of Constitutive and Inducible Maize Kernel Proteins of Genotypes Resistant or Susceptible to Aflatoxin Production. J. Food Prot. 2001; 64(11): 1785-1792.

44. Huang Z, White DG and GA Payne Corn Seed Proteins Inhibitory to Aspergillus flavus and Aflatoxin Biosynthesis. Phytopathology 1997; 87(6): 622-627.

45. Lozovaya VV, Waranyuwat $\mathbf{A}$ and JM Widholm beta-1,3-glucanase and Resistance to Aspergillus flavusInfection in Maize. Crop Sci. 1998; 38(5) :12551260 .

46. Atehnkeng J, Ojiambo PS, Ikotun T, Sikora RA, Cotty PJ and R Bandyopadhyay Evaluation of Atoxigenic Isolates of Aspergillus flavus as Potential Biocontrol Agents for Aflatoxin in Maize. Food Addit. Contam. Part A. 2008; 25(10): 1264-1271.

47. Barros G, Magnoli C, Reynoso M, Ramirez M, Farnochi M, Torres A, Dalcero M, Sequeira J, Rubinstein $\mathbf{C}$ and $\mathbf{S}$ Chulze Fungal and Mycotoxin Contamination in Bt Maize and Non-Bt Maize Grown in Argentina. World Mycotoxin J. 2009; 2(1): 53-60. 


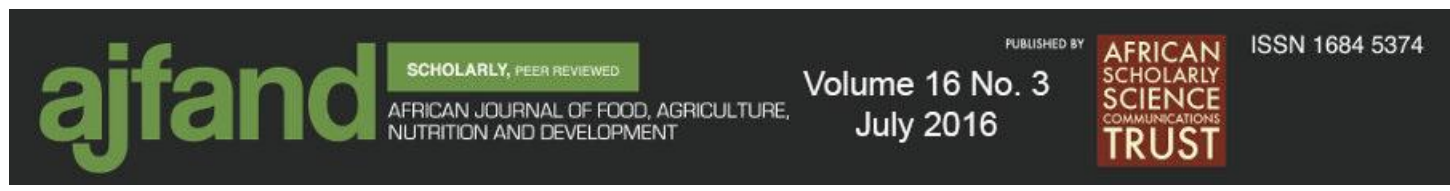

48. Munkvold GP Cultural and Genetic Approaches to Managing Mycotoxins in Maize. Annu. Rev. Phytopathol. 2003; 41: 99-116.

49. Fakhoury AM and CP Woloshuk Amy1, the alpha-Amylase Gene of Aspergillus flavus: Involvement in Aflatoxin Biosynthesis in Maize Kernels. Phytopathology 1999; 89(10): 908-914.

50. Rajasekaran K, Cary JW, Cotty PJ and TE Cleveland Development of a GFPExpressing Aspergillus flavus Strain to Study Fungal Invasion, Colonization, and Resistance in Cottonseed. Mycopathologia 2008; 165(2): 89-97.

51. Yin C, Jurgenson JE and SH Hulbert Development of a Host-induced RNAi System in the wheat Stripe Rust Fungus Puccinia striiformis f. sp. tritici. Mol. Plant-Microbe Interact. 2011; 24(5): 554-561.

52. Koch A, Kumar N, Weber L, Keller H, Imani J and K-H Kogel Host-induced Gene Silencing of cytochrome P450 lanosterol C14 -demethylase-encoding Genes Confers Strong Resistance to Fusarium species. Proc. Nat. Acad. Sci. USA 2013; 110(48): 19324-19329.

53. Yu J Current understanding on aflatoxin biosynthesis and future perspective in reducing aflatoxin contamination. Toxins 2012; 4(11): 1024-1057.

54. Reverberi M, Punelli M, Smith CA, Zjalic S, Scarpari M, Scala V, Cardinali G, Aspite N, Pinzari F, Payne GA, Fabbri AA and C Fanelli How Peroxisomes Affect Aflatoxin Biosynthesis in Aspergillus flavus. PLOS ONE 2012; 7(10): e48097.

55. Masanga JO, Matheka JM, Omer RA, Ommeh SC, Monda EO and AE Alakonya Downregulation of Transcription Factor aflR in Aspergillus flavus Confers Reduction to Aflatoxin Accumulation in Transgenic Maize with Alteration of Host Plant Architecture. Plant Cell Rep. 2015; 34(8): 1379-1387.

56. Hell K and C Mutegi Aflatoxin Control and Prevention Strategies in Key Crops of Sub-Saharan Africa. Afr. J. Microbiol. Res.2011; 5(5): 459-466.

57. ACDI-VOCA. Drying and Storage for Aflatoxin Prevention: Annual Report, November 2013 - March 2015. ACDI-VOCA, Nairobi. 2014. 